\title{
Moving from incremental to transformational change in climate adaptation policy? : An institutionalist perspective
}

\section{Munck af Rosenschöld, Johan}

Edward Elgar

2019-02-28

Munck af Rosenschöld , J \& Rozema , J G 2019, Moving from incremental to transformational change in climate adaptation policy? An institutionalist perspective . in E C H Keskitalo \& B L Preston (eds), Research Handbook on Climate Change Adaptation Policy . , 4 , Edward Elgar , Cheltenham , pp. 91-107 . https://doi.org/10.4337/9781786432520.00012

http://hdl.handle.net/10138/306475

https://doi.org/10.4337/9781786432520.00012

acceptedVersion

Downloaded from Helda, University of Helsinki institutional repository.

This is an electronic reprint of the original article.

This reprint may differ from the original in pagination and typographic detail.

Please cite the original version. 
This is a post-print version of the chapterl. The final version is available in Research Handbook on Climate Change Adaptation Policy edited by E.C.H. Keskitalo and B.L. Preston, published in 2019, Edward Elgar Publishing Ltd https://doi.org/10.4337/9781786432520.00012

The material cannot be used for any other purpose without further permission of the publisher, and is for private use only.

\title{
Moving from incremental to transformational change in climate adaptation policy? An institutionalist perspective
}

\author{
Johan Munck af Rosenschöld \& Jaap G. Rozema
}

\begin{abstract}
In this chapter we address the relationship between climate adaptation strategies and the broader institutional context. Institutions, we argue, shape policy responses to climate change. Questions in the literature have been raised whether incremental, often technocratic, adaptation strategies are sufficient to address the future risks of climate change. Instead, broader societal transitions and transformations may be required, embedded in adaptation strategies resulting from drastic, catalytic change. Transformational policy responses to climate change are apt to reshape interactions between, and within, human and natural systems. However, scaling up adaptation strategies to spur catalytic change encounters significant institutional constraints, leading to inertia. We study the adaptation literature to discern drivers that generate institutional inertia and discuss their implications for employing incremental and transformational adaptation strategies. These drivers are also discussed critically by exploring how institutional inertia can be challenged.
\end{abstract}

\footnotetext{
${ }^{1}$ To cite: Munck af Rosenschöld, J. \& Rozema, J.G. 2019. Moving from incremental to transformational change in climate adaptation policy? An institutionalist perspective. In E.C.H. Keskitalo \& B.L. Preston, eds. Research Handbook on Climate Change Adaptation Policy. Cheltenham: Edward Elgar Publishing Limited, pp. 91-107.
} 


\section{INTRODUCTION}

There have been an increasing amount of calls for wide-ranging transformational change to societal structures to address climate change (O'Brien 2016). However, multiple drivers of institutional inertia slow down action in the international sphere (Munck af Rosenschöld et al. 2014). Dangerous climate change marks a planetary boundary (Steffen et al. 2015), the effects of which are significant once past a certain tipping point (Lenton et al. 2008). Yet, as some regions are more vulnerable than others due to their geographical location and position in the globalized economic system, impacts are being felt and appraised differently across the globe (O'Brien \& Leichenko 2000). Climate-related hazards are an elusive category of disruptive natural calamities, as they often coincide with other environmental problems - and compounded by socio-economic, demographic, or cultural factors. Despite apparent tensions and challenges in addressing climate change effectively, it is noted that adopting appropriate climate adaptation policies directed toward maintaining social and ecological resilience has become increasingly politically legitimate. This can be discerned in the recently adopted UNFCCC Paris Agreement, stressing the importance of adaptation in climate policy (Mogelgaard et al. 2016), as well as in an increase in adaptation funding on a global scale (Termeer et al. 2017). Because of the increasing complexity of society and connectedness between societal sectors, regions, countries, and beyond, the role of public policy to structure adaptation practices and strategies and more autonomous efforts enacted by nongovernmental actors have been emphasized (Bauer et al. 2012; Mees et al. 2012; see also Chapter 23).

The development of adaptation policy and strategies has been discussed in the literature broadly along the lines of incremental and transformational change (see e.g. Pelling 2011). Incremental change has been the dominant response within climate adaptation (Smit \& Wandel 2006). Incremental change includes efforts to act on adaptation through technical and standardized means within the boundaries of existing systems, generating small-scale changes to practices and conventions (Dewulf 2013), on a continuous, linear basis. Yet, these change processes are expected to have low returns, as they do not question the central assumptions of, and justifications for, established norms of adaptation. Incremental change can, in other words, be seen as an expression of 'business as usual', focusing on reacting towards perceived and experienced extreme weather events (Storbjörk \& Hedrén 2011). Technical solutions may generate new understandings that are beneficial for the implementation of adaptation strategies, but are likely not giving rise to significantly different visions of future possible action. Dissatisfaction with the incremental approach to climate adaptation has generated calls for more disruptive approaches to induce transformational changes. Transformational change is often viewed as a process where rules and norms, having been (more or less) stable for a certain period of time, experience disruption followed by events that allow for new development trajectories to emerge. Transformational change entails adopting a future-oriented approach, which acknowledges the need for dynamism, uncertainty, resilience, and learning in adaptation (Eakin et al. 2016). Returns are high, as the process delegitimizes the foundations of extant structures. It is worth noting that transformational 
change has a clear normative dimension - not all forms of transformation or disruption of the status quo are deemed desirable. Transformation is tied to the notion that wide-ranging changes are needed to sufficiently address the dangers of climate change.

In this chapter we focus on institutions as structuring adaptation measures and explore the role of institutions in incremental and transformational changes in the context of climate change adaptation on the local level in the Global North. The literature on climate change adaptation has focused a great amount on various forms of 'barriers' to effectively developing and implementing policy (e.g. Adger et al. 2009; Amundsen et al. 2010; Bisaro et al. 2010; Jones \& Boyd 2011; Measham et al. 2011; Lehmann et al. 2015; see also Chapter 19; Chapter 30). By highlighting examples from studies in the adaptation literature, we illustrate how institutions shape change processes, thereby providing an overview of the structural elements of change. Relying on the literature on 'new institutionalism', we understand institutions to be the formal and informal rule systems, norms, and routines that mediate climate adaptation across all scales of public policymaking. Institutions thus have an important role in shaping which adaptation strategies are viewed as acceptable, viable, and appropriate.

Initiating transformational changes has proven to be challenging due to the inertial qualities of institutions (e.g. Munck af Rosenschöld et al. 2014). One of the central traits of institutions is that they are stable (Hoffman 2011) and tend to reinforce the status quo. Institutions can be conceptualized as "relatively enduring features of political and social life (rules, norms, procedures) that structure behavior and that cannot be changed easily or instantaneously" (Mahoney \& Thelen 2010, p.4, italics in original). Put differently, the formal and informal rule systems and norms tend to steer towards predetermined outcomes, notwithstanding a shared concern of urgency in policy circles or across society at large to respond to climate change. We thus treat the stability of institutions as the main explanation for the difficulties of moving from incremental to transformational change. By default, institutions are not inherently "good" or "bad", but bring about stability to social interaction. The appropriateness or 'fit' (e.g. Olsson et al. 2010) of certain institutional arrangements need to be assessed in relation to the context in which they operate.

An institutional approach to adaptation enables the researcher to consider the more ingrained and socially rooted dimensions of adaptation. While adaptation measures are, in effect, acted upon by a variety of societal actors, these measures thus need to be situated in their broader institutional context in order to understand adaptation processes more comprehensively (Adger et al. 2005); adaptive capacity to tackle the adverse effects of climate change does not develop in institutional vacuum (Amaru \& Chhetri 2013). This means we should consider adaptation policy to be significantly shaped by existing institutional orders, thereby accepting the limits of individual, autonomous action. An institutional approach also questions the notion of the rational actor, who makes decisions based on an "objective" self-interest. Instead, individuals and organizations are guided by 'bounded rationality' - they “choose 'good enough' responses that conform to normative 
ideas of appropriate behavior, rather than optimizing across the full universe of potential options" (Berkhout 2012, p.93). More broadly, with its emphasis on the social dimension of climate change adaptation, a focus on institutions highlights the usefulness of social science in understanding the failures and successes of adaptation.

\section{HOW DO INSTITUTIONS INFLUENCE CLIMATE CHANGE ADAPTATION?}

In this section we discuss the significance of institutions in adaptation policy by drawing insights from the new institutionalist literature. The focus will be on how rules, norms, routines, and cognitive scripts influence adaptation policy and attempts to induce change. Since the 1980 s, the new institutionalist approach has been widely used in the field of climate change and environmental policy more broadly, studying how institutions, influence behavior (e.g. O'Riordan \& Jordan 1999; Hotimsky et al. 2006; Munck af Rosenschöld et al. 2014). New institutionalism can be seen as an umbrella term for a wide array of research and disciplines, including economics, political science, and sociology, aiming to assess the interplay between institutions and human behavior (Hall \& Taylor 1996; March \& Olsen 1989; Koelble 1995). The emergence of the new institutionalist literature can be seen partly as a reaction to the behavioralist view of human agency that dominated especially political science during the mid- $20^{\text {th }}$ century, assigning individual behavior as the cornerstone for analysis (Immergut 1998). New institutionalism is critical of the usefulness and appropriateness of the sole focus on human behavior, and instead considers the institutional environment in which behavior is set.

New institutionalism can be divided into four separate streams of research. First, rational choice institutionalism regards institutions as external rules and norms, either formal or informal, that constrain the self-maximizing behavior of individuals and organizations (Olson 1965; Ostrom 1990; North 1990). Second, historical institutionalism also regards institutions as rules and norms, yet compared to the rational choice stream it does not conceptualize them as existing outside the actor. Much of the research within historical institutionalism focuses on path dependence, i.e. how decisions made in the past influence the present, including political conflict, and how that influences behavior (Peters et al. 2005; Pierson 2004). Third, sociological institutionalism arguably applies an arguably broader ontological approach to institutions, which are conceptualized as rules, values, routines, and symbols. It emphasizes the socializing elements of institutions in forming individuals' preferences (cf. rational choice institutionalism). Fourth, discursive institutionalism, the most recent 'new institutionalism', places emphasis on the significance of ideas and how these are discursively constructed and communicated across actors (Schmidt 2008). From the literature on new institutionalism it becomes clear that institutions are not only regulative, through laws and rules that constrain behavior, but also enable certain conditions for human actions through norms, routines, and cognitive maps (Scott 1995). 
The different ways of understanding the interaction between institutions and behavior also have important implications for how the linkage between institutions and adaptation policy is conceptualized. If one gives precedence to the notion of institutions as formal rules and regulations existing "outside" of the actor (as is common in rational choice institutionalism), institutions can be seen as tools within the policy toolbox (Tennekes et al. 2013). Here, institutions are broadly understood as means to implement policy, and they may be sufficient or insufficient for the task. If one takes the socializing dimension of institutions seriously (as in sociological institutionalism), the link between institutions and policy becomes arguably more complex. Norms and conventions of commonly accepted behavior form the context in which policy is formulated and implemented (Hukkinen 1999). These informal institutions set the scope of which types of adaptation strategies and action is considered desirable and viable, and have a tendency to favor the existing dominant institutional order within a specific context. This is not to say that individuals and organizations have no agency vis-à-vis institutions (see the Concluding discussion section in this chapter), but that institutions have important influence on behavior.

In the following, by using examples from studies in the adaptation literature we show how institutions guide adaptation and the challenges of instigating change. Our goal here is not to classify studies according to strands of institutionalism, but to explore the role of institutions, both formal and informal, in slowing down changes in adaptation. Nor do we wish to conduct an exhaustive review of the literature on institutions in adaptation, but rather to focus on the central concepts that guide the literature on the interface between institutions and polity, policy, and politics. In addition, the compartmentalization of institutions into formal and inform is mainly analytical. Both forms of institutions are interrelated, as written laws, rules, and regulations are acted on by actors with differing understandings, priorities, and customs, which influence how formal institutions are materialized 'on the ground'.

\section{Formal institutions of adaptation}

Formal institutions, in the context of climate adaptation, are the rule systems that guide policy action in addressing adverse effects of climate change. They can be laws, regulations, protocols, directives, manuals or other policy loci exhibiting rule competence and exerting claims of, and to, authority (see also Chapter 4; Chapter 19). Climate adaptation has become a central tenet of public policy-making due to increasing public concern over climatic effects, and subsequently has found its way into formal institutions. In Europe, Massey and Huitema (2015) have found that adaptation has become a stand-alone policy field in 15 out of 27 countries investigated, while adaptation is also mainstreamed into other policy fields through innovation and learning. Furthermore, climate adaptation - in contrast to climate mitigation - is a public policy field that could yield immediate results. It could mark a 'quick win' for policy-makers, especially when embedded in the narrative of public safety (Wilbanks \& Kates 2010). Nevertheless, climate adaptation is still far away from being on a par with other domains of public policy, such as education and agriculture. State 
departments responsible for the environment are still relatively young compared to departments dealing with policy domains typically associated with the welfare state. Being the "new kid in town", climate adaptation policy struggles for resources when public spending priorities are set, in particular during times of austerity.

As adverse effects of climate change are often experienced locally, decisions on climate adaptation measures often bear an inherent local character. As a consequence, the engagement of local authorities with climate adaptation has been a prime object of study (e.g. Amundsen et al. 2010; Cashmore \& Wejs 2014; Næss et al. 2005; Juhola \& Westerhoff 2011). Some of these authors have pointed out that climate adaptation is not always a key priority when shaping formal institutions. Næss et al. (2005) argue that adequate climate adaptation policy at the local level should also be in the national interest for it to become a spending priority. Where such convergence is absent, specific local demands for appropriate adaptation measures lack codification in rules specifically dealing with local situations. Their study of climate adaptation in two local municipalities in Norway demonstrate that local knowledge changed national adaptation policy only to a marginal extent. This could have to do with the relative novelty of climate adaptation as a field of state intervention, but it is also dependent on the tiering of policy scales. In their comparison of Finland and Italy, Juhola and Westerhoff (2011) show in what way climate adaptation has evolved as a state responsibility, and whether or not this has ensued from collaboration between the local and the national levels. In the case of Finland, they find that local adaptations efforts develop in relative autonomy despite a national effort to mainstream climate adaptation into policy-making.

Recent research also exposes a mismatch between climate projections and formal institutions at the local level (Lorenz et al. 2017). In many instances formal institutions induce capacity or resource constraints, suggesting rule systems have little impact in real-world decision-making. Budgetary constraints can be the reason for this, as is epistemic uncertainty associated with the validity of such projections from a juridical-technical sense. Porter and colleagues (2015) show from their longitudinal dataset on progress made on climate adaptation at the local level that political commitment correlates heavily to availability of funds. Statutory responsibilities require the lion's share of funding, which means that decisions made in the past dictate spending priorities in the present.

Aside from public spending priorities, climate adaptation is a fundamentally different public policy field compared to more conventional fields of state intervention. McDonald (2011) asserts that climate change, as public policy problem, has unique - but persistent - properties that challenge the ability of formal institutions to adapt. Protagonists of climate action often refer to projections indicating the urgent need to remediate adverse climatic effects. However, despite no shortage of scientific data hinting at such future effects, formal institutions can either exhibit low adaptive capacity or fail to internalize climate projections as a precursor and justification of taking appropriate adaptation measures (see Næss et al. 2006). This can be due to the underprivileged role of scientific evidence in political decision-making (Juntti et al. 2009), meaning that formal 
institutions are not revised periodically to converge to progress make in the scientific realm (but see Chapter 27). Subsequently, scientific findings (such as those by the Intergovernmental Panel on Climate Change (IPCC)) are possibly received with skepticism by local policy-makers because of the dominance of rule systems in decision-making (Porter et al. 2015). This suggests that formal institutions shape policy action, notwithstanding them being obsolete or insufficient in respect to what scientific discovery can tell us about the adverse impacts of climate change. Where resistance to scientific proof endures notwithstanding availability of financial resources, scientific consensus and the absence of legal constraints, localities could feel it unfair or simply beyond their responsibility to counter an inherently global phenomenon - even when its effects are experienced within their jurisdiction.

Formal institutions at the national level can restrict the ability of local governments to respond to adaptation challenges. For example, national rule frameworks on water security are put in place to protect the land against flooding but not against over-precipitation. As such, locally experienced problems are not defined in national policy terms. In the case of flooding, local policy-makers need to find their own operating space in enhancing adaptive capacity when national policy cannot guarantee local safety entitlements (cf. Harries \& Penning-Rowsell 2011). Amundsen and colleagues (2010) find that formal institutions can lack the kind of flexibility to differentiate policy following particular local needs. This is especially cumbersome in centralized states, if they are slow in recognizing the immediate local threat posed by the effects of climate change. Unclear roles and expectations as well as legal constraints to regulate water use on the local level, for example to withstand prolonged dry periods, can hinder local governments from adopting a position of relative autonomy in making climate adaptation policy (Ivey et al. 2004).

Where appropriate, in the literature the link between international, supranational, intergovernmental, or national formal institutions and local government is explicitly sought, because of devolving responsibilities from top to bottom (Bulkeley \& Kern 2006), and because of the need for multi-level governance regimes to deal with the effects of climate change (Pahl-Wostl 2009). Policy transfers between policy scales ideally lead to knowledge exchange across levels, so as to induce social learning (Næss et al. 2005; Glaas et al. 2010; Pahl-Wostl 2009; see also Chapter 9). Such learning processes have the potential to change the formal institutions encompassing regulations on climate adaptation, through a process of 'formalization' (Næss et al. 2005). Social learning, subsequently, would then lead to a change in climate adaptation practices. Rules emanate from the interplay between knowledge systems - fleshed out across different policy scales - on what kind of measures are required given the urgency to adapt.

At the same time, localities seem to attract attention precisely because of the absence of discretion in the policy hierarchy. Cities have increasingly found traction in the climate adaptation literature as arenas for climate redress (e.g. Bulkeley \& Betsill 2013), where they have been posited as able to mobilize policy resources when faced with adverse climatic effects. Furthermore, plausibly as a consequence of progressive politics, cities take a leadership role in climate adaptation to 
demonstrate best-practice and entrepreneurship. Paradoxically, perhaps, lack of formal institutions associated with climate adaptation at the local level has fostered climate action, thus at the backdrop of "few policies, professional norms, and examples to guide their efforts" (Anguelovski \& Carmin 2011, p.169; see also Storbjörk \& Hedrén 2011). It leaves to wonder how important vertical integration of climate adaptation across policy scales through formal institutions is for taking appropriate measures (see also Juhola \& Westerhoff 2011).

\section{Informal institutions of adaptation}

Institutions do not only exist as external entities that influence agency, but also form the context in which adaptation occurs and new strategies emerge (Tennekes et al. 2013). Research focusing on informal institutions, including norms and cognitive scripts (March \& Olsen 1989; Powell \& DiMaggio 1991), often view the relationship between institutions and behavior as multifaceted. Not only do institutions influence behavior of actors, but they also structure the conditions for which types of behavior are regarded as legitimate. Understanding the informal institutions of adaptation is crucial, as they highlight how structures are made sense of and acted on.

The literature exploring informal institutions has focused on the framings, discourses, and routines in explaining that shape climate adaptation. Framings can be seen to originate from discourses nested in institutions, and shape which questions are focused on and what kind of knowledge is favored in developing adaptation measures (O'Brien et al. 2007). The framing of adaptation - either as tame, technical problems that can be addressed through existing means, or as broader 'wicked' problem with multifaceted ramifications for social and political affairs, including questions of inequality and uncertainties - has important implications for which types of adaptation measures are implemented (Dewulf 2013). Seeing adaptation as a "controllable" problem would assume that it can be dealt with in a structured manner, often confined to individual sectors or policy actors (see also Chapter 27). From this point of view, closing the debate about the width of the problem and the uncertainties relating to adaptation may lead to biases for limited, technological responses to a problem that requires more comprehensive strategies (Dewulf 2013).

Studying the different framings of adaptation strategies in four European countries, Juhola and colleagues (2011) note that uncertainties embodied in modeling and predicting climate change impacts may cause local policy-makers to concentrate on vulnerabilities that are presently identifiable, rather than taking seriously the risks of changes generated by climate change in the future. Failing to deal with uncertainties thus reinforces existing adaptation strategies (see also Chapter 10; Chapter 30). Focusing on frames favoring reactive measures in adaptation, for example "fixing" damage to infrastructure caused by extreme events, serves to limit the scope for considering the broader social implications of such events, such as unequal exposure of populations, and anticipating future climate risks (Adger et al. 2005; O’Brien et al. 2007). 
In another study, Tennekes and colleagues studied path dependencies in adaptation policy in the Netherlands from the point of view of legitimacy, or the "substantive and procedural fairness and to the extent to which decisions are acceptable to stakeholders and participants in policy processes" (Tennekes et al. 2013, p.242). Adaptation strategies that are in line with expectations in an institutional setting are considered legitimate to the extent that these strategies become taken for granted. Conversely, alternative strategies that would involve significant changes in terms of who benefits and pays for certain adaptation measures or cooperation across governmental levels are likely to be regarded as illegitimate and subsequently opposed (Inderberg 2011). This is similar to what Termeer and colleagues (2017) call 'social' and 'cognitive fixations': the inability to reconsider who are involved in adaptation and what kind of ideas are put forward. By focusing on climate adaptation planning in Aarhus, Denmark, Cashmore and Wejs (2014) found that legitimacy was constructed through the engagement of business actors. By presenting adaptation measures as business opportunities, the 'Climate Secretariat', the municipal body in charge of climate planning, deployed climate change as a discursive catalyst for initiating green growth and economic development.

Informal institutions are also materialized in institutionalized professional roles. The familiarity of certain professional, work-related routines, coupled to conceptions of self-identity, tends to discourage the inclusion of new forms of activities (Kates et al. 2012). Harries and PenningRowsell (2011) studied the creation of a strategy on flood risk management in South East England amid the development of government policies pushing for diversity in adaptation. Their study shows that decision-makers were operating in an 'engineering' paradigm, favoring discourses such as 'flood defense', thus concentrating on building physical infrastructure to protect the land from extreme weather events. The engineering social identity was seen to hinder the forming of alternative adaptation practices that challenged the existing paradigm. Their study shows that, although adaptation policy formed on the national level may shift toward favoring inclusion and a wider knowledge base, the implementation of that policy on lower levels of government may limit its transformative potential. From a similar perspective, Storbjörk and Hedrén (2011) explored the role of professional interests and cultures in coastal zone management in a Swedish municipality. While the authors stress the importance of key actors in driving change, they also identified apparent ineffective policy coordination between administrative sub-units within the municipality. The unwillingness by the different sectors to assume a larger role in adaptation, due to ingrained work-related routines and practices within the individual departments, was seen to stifle efforts to implement adaptation across sectors. Klein and colleagues (2016) show in their study of 'networked' implementation of urban climate adaptation in Helsinki, Finland, that conflicting planning paradigms embodied in participating organizations incite struggles over legitimacy, which hinders the effective implementation of adaptation. 


\section{CONCLUDING DISCUSSION}

This concise overview of the literature examining institutions in the context of climate adaptation raises pertinent questions about the structural conditions mediating efforts to move beyond incremental change. It is evident that investigating the role of institutions and institutional inertia is crucial if we aim to assess the challenges of instigating transformational change. The focus on formal and informal institutions directs our attention to how rules, norms, and social codes shape practices, and how they are resisting change. Furthermore, they help explain the absence of effective policies in higher levels of government, or how policies may fail to achieve their goals. It thus underlines the importance of context and the need for scale-sensitive analyses to gain a more comprehensive understanding of the adaptation policy process.

As shown elsewhere (Munck af Rosenschöld et al. 2014), the analytical exercise of mapping out single drivers or mechanisms that guide policy efforts to address climate change can be beneficial for making sense of institutions. Nevertheless, the existence of different drivers is likely, thus obscuring a straightforward explanation for the influence of institutions on climate adaptation. We will here concentrate on central concepts and patterns identified in this chapter and their implications on incremental and transformational change. We will also discuss how institutional inertia can be addressed, thereby giving impetus to analysis of transformational potential of agency. Such an approach serves as a counterweight to structural (over)determination that sometimes exists in institutional analyses (for a more detailed discussion on the study of agency in institutional settings see e.g. Battilana \& D'Aunno 2009; Beunen \& Patterson 2016).

The struggles of moving from incremental toward transformational change has been identified in this chapter through different drivers, including resource allocation, uncertainty, and legitimacy deficits. Resource allocation affects change processes in that they set limits to what types of climate adaptation activities are favored. It is evident that budgetary constraints serve as an obstacle to developing more transformational responses to climate change, not least on lower levels of government, where adaptation efforts need to be balanced against other, often costly, statutory, executive responsibilities, such as the provision of health care and education. One way around budget cuts and austerity measures has been to outsource governmental functions and deepen the involvement of private and voluntary sectors in public service delivery and innovation development, often organized in projects (Godenhjelm et al. 2015). In environmental policy and planning, the utilization of project organizations has been put forward as a potential strategy to create innovations with limited budgets and clear end dates as well as involve actors across sectors (Sjöblom \& Godenhjelm 2009; Bauer \& Steurer 2014; Munck af Rosenschöld \& Wolf 2017; see also Chapter 5). While research shows that the capacity of projects to create new knowledge and diffuse it to other organizations varies across countries and regions, a clear focus on the organization and practices of short-term adaptation projects would be beneficial for understanding 
how transformational institutional change processes within climate adaptation policy can be initiated and nurtured.

Uncertainty pertaining to climate modeling - in this case with respect to the adverse effects of climate change - seem to instigate reacting to immediate threats rather than proactively adopting a more comprehensive approach to vulnerability. Policy-makers may perceive scientific uncertainty as too shaky a foundation for addressing the broader structures of effective climate adaptation, which reinforces institutional inertia. However, Adger and colleagues (2009) contend it is problematic to frame uncertainty as an obstacle. They propose a 'robust' decision-making strategy where policy-makers "systematically examine the performance of their adaptation strategies over a wide range of plausible futures driven by uncertainty about the future state of climate and many other economic, political and cultural factors" (Adger et al. 2009, p.344). Acknowledging the persistence of uncertainty in climate modeling is thus essential when designing and implementing adaptation strategies that are intended to break the status quo.

Uncertainty also relates to the problem of scale. Unclear responsibilities between governmental departments and between levels of government can challenge institutional change in adaptation policy. Conversely, as was shown earlier, uncertainty can also be a stepping stone for entrepreneurial action in the absence of institutionalization higher up the policy chain. Local governments may choose in their own remit to proactively take a leadership position in adaptation amid unclear political mandates and legislation. This is especially true for cities and coastal areas. Uncertainty provides leeway for local governments to develop climate adaptation policy more suitable to their circumstances. Studying how uncertainty is debated, contested, and acted on among decision-makers thus provides additional insight into how efforts to move beyond incremental change are realized and challenged.

Legitimacy - or lack thereof - also emerged as a central issue in this chapter. The centrality of legitimacy in understanding institutional change in the context of adaptation is clear and reflects the important role of legitimacy in the new institutionalist literature more generally. In this chapter, we discussed legitimacy with respect to professional identities and work cultures, both of which influence why certain actions are favored and disapproved. Proposed actions that challenge deeply ingrained professional roles and expectations as well as habits of organizing work are likely to be delegitimized by the actors involved. As we have shown, legitimacy struggles on the local level can weaken even proactive policy initiatives enacted on the national level. This shows that clear signals sent out by national level policy is not necessarily enough to incite changes on all levels of government. Legitimacy is not, however, necessarily a 'one-way street' of obstructing change, transformational or otherwise. Legitimacy can be strengthened, particularly by investing in consensus on taking appropriate action. By broadening the knowledge base on the local level and including diverse set of actors (e.g. governmental. non-governmental, hybrid and boundary organizations active in the science-policy interface), a wider array of legitimacy claims can be introduced that challenge conventional frames of how effective adaptation should be realized (but 
see Klein et al. 2016). Supporting and reinforcing frames that favor adopting a broader approach to adaptation, rather than relying on technological fixes, could be a way to challenge institutional inertia.

This chapter has highlighted the institutional factors that guide and, more often than not, slow down climate adaptation initiatives. It shows the struggles of achieving transformational change and how existing institutional orders influence efforts to achieve changes to business-as-usual approaches. Importantly, the implications of institutional inertia vary across space and scale. It is evident that the impacts of climate change is, and will be, felt asymmetrically in regions across the globe, not only due to their physical location, but also their position in the globalized market structure (O'Brien \& Leichenko 2000). As mentioned earlier, transformation in the context of climate change adaptation has a clear normative dimension - transformation entails initiating large-scale changes that serve to render our responses to climate change in the present and future more effective. By being a normative concept, it is at the same time subject to contestation. As Adger and colleagues have contended, "the choice of how an environmental governance problem is handled within a jurisdiction is a reflection of the strength of the interests and power of the actors who define the problem" (Adger et al. 2005, p.80). Institutional inertia is clearly linked to the notion of power, where certain political and economic actors are able to exert their influence by slowing down change processes (Munck af Rosenschöld et al. 2014; but see Chapter 24). Addressing this imbalance requires a strong focus on social justice as a guiding principle for action (Pelling 2011), and an appreciation that institutional inertia is not merely a technical issue, but one that involves social and political contestation and struggles (see also Chapter 7). This again emphasizes the significance of social science in articulating more nuanced perspectives on adaptation.

To conclude on a (somewhat) more positive note, institutional change needs to be seen in relation to the time frame of change. Termeer and colleagues (2017) argue that achieving transformational change, by them understood as involving changes that are simultaneously deep, wide, and quick, is improbable. From this perspective, incremental changes need not be slow, and they may eventually lead to transformational changes to climate adaptation in the long run. As has been discussed, institutions are, per definition, relatively stable, which limits the prospects of drastic institutional change. However, existing institutions are constantly supported, contested, legitimized, and delegitimized, which underscores the 'fluidity' of institutional inertia and the possibilities of generating more wide-ranging changes to climate adaptation in the long run. 


\section{References}

Adger, W.N. et al., 2009. Are there social limits to adaptation to climate change? Climatic Change, 93(3-4), pp.335-354.

Adger, W.N., Arnell, N.W. \& Tompkins, E.L., 2005. Successful adaptation to climate change across scales. Global Environmental Change, 15(2), pp.77-86.

Amaru, S. \& Chhetri, N.B., 2013. Institutional response to environmental constraints, and the need for increased flexibility, participation, and integration of approaches. Applied Geography, 39, pp.128-139.

Amundsen, H., Berglund, F. \& Westskogh, H., 2010. Overcoming barriers to climate change adaptation-a question of multilevel governance? Environment and Planning C: Government and Policy, 28(2), pp.276-289.

Anguelovski, I. \& Carmin, J., 2011. Something borrowed, everything new: Innovation and institutionalization in urban climate governance. Current Opinion in Environmental Sustainability, 3, pp.169-175.

Battilana, J. \& D'Aunno, T., 2009. Institutional work and the paradox of embedded agency. In T. B. Lawrence, R. Suddaby, \& B. Leca, eds. Institutional Work: Actors and Agency in Institutional Studies of Organizations. Cambridge: Cambridge University Press, pp. 31-58.

Bauer, A., Feichtinger, J. \& Steurer, R., 2012. The Governance of Climate Change Adaptation in 10 OECD Countries: Challenges and Approaches. Journal of Environmental Policy \& Planning, 14(3), pp.279-304.

Bauer, A. \& Steurer, R., 2014. Innovation in climate adaptation policy: are regional partnerships catalysts or talking shops? Environmental Politics, 23(5), pp.818-838.

Berkhout, F., 2012. Adaptation to climate change by organizations. Wiley Interdisciplinary Reviews: Climate Change, 3(1), pp.91-106.

Beunen, R. \& Patterson, J.J., 2016. Analysing institutional change in environmental governance: exploring the concept of "institutional work." Journal of Environmental Planning and Management, pp.1-18.

Bisaro, A., Wolf, S. \& Hinkel, J., 2010. Framing climate vulnerability and adaptation at multiple levels: Addressing climate risks or institutional barriers in Lesotho? Climate and Development, 2(February 2013), pp.161-175.

Bulkeley, H. \& Betsill, M.M., 2013. Revisiting the urban politics of climate change. Environmental Politics, 22(1), pp.136-154. 
Bulkeley, H. \& Kern, K., 2006. Local Government and the Governing of Climate Change in Germany and the UK. Urban Studies, 43(12), pp.2237-2259.

Cashmore, M. \& Wejs, A., 2014. Constructing legitimacy for climate change planning: A study of local government in Denmark. Global Environmental Change, 24, pp.203-212.

Dewulf, A., 2013. Contrasting frames in policy debates on climate change adaptation. Wiley Interdisciplinary Reviews: Climate Change, 4(4), pp.321-330.

Eakin, H. et al., 2016. Cognitive and institutional influences on farmers' adaptive capacity: insights into barriers and opportunities for transformative change in central Arizona. Regional Environmental Change, 16(3), pp.801-814.

Glaas, E. et al., 2010. Managing climate change vulnerabilities: formal institutions and knowledge use as determinants of adaptive capacity at the local level in Sweden. Local Environment, 15(6), pp.525-539.

Godenhjelm, S., Lundin, R.A. \& Sjöblom, S., 2015. Projectification in the public sector - the case of the European Union. International Journal of Managing Projects in Business, 8(2), pp.324-348.

Hall, P.A. \& Taylor, R.C.R., 1996. Political Science and the Three New Institutionalisms. Political Studies, 44(5), pp.936-957.

Harries, T. \& Penning-Rowsell, E. 2011. Victim Pressure, Institutional Inertia and Climate Change Adaptation: The Case of Flood Risk. Global Environmental Change, 21(1), pp.188197.

Hoffman, A.J., 2011. The culture and discourse of climate skepticism. Organization, 9(1), pp.7784.

Hotimsky, S., Cobb, R. \& Bond, A., 2006. Contracts or Scripts? A Critical Review of the Application of Institutional Theories to the Study of Environmental Change. Ecology and Society, 11(1), p.41.

Hukkinen, J., 1999. Institutions of Environmental Management: Constructing Mental Models and Sustainability, London \& New York: Routledge.

Immergut, E.M., 1998. The Theoretical Core of the New Institutionalism. Politics \& Society, 26(1), pp.5-34.

Inderberg, T.H., 2011. Institutional constraints to adaptive capacity: adaptability to climate change in the Norwegian electricity sector. Local Environment, 16(4), pp.303-317.

Ivey, J.L. et al., 2004. Community Capacity for Adaptation to Climate-Induced Water Shortages: Linking Institutional Complexity and Local Actors. Environmental Management, 33(1), 
pp.36-47.

Jones, L. \& Boyd, E., 2011. Exploring social barriers to adaptation: Insights from Western Nepal. Global Environmental Change, 21(4), pp.1262-1274.

Juhola, S., Keskitalo, C. \& Westernhoff, L., 2011. Understanding the Framings of Climate Change Adaptation Across Multiple Scales of Governance in Europe. Environmental Politics, 20(4), pp.445-463.

Juhola, S. \& Westerhoff, L., 2011. Challenges of adaptation to climate change across multiple scales: A case study of network governance in two European countries. Environmental Science and Policy, 14(3), pp.239-247.

Juntti, M., Russel, D. \& Turnpenny, J., 2009, Evidence, Politics and Power in Public Policy for the Environment. Environmental Science \& Policy, 12 (3), 207-215.

Kates, R.W., Travis, W.R. \& Wilbanks, T.J., 2012. Transformational adaptation when incremental adaptations to climate change are insufficient. Proceedings of the National Academy of Sciences of the United States of America, 109(19), pp.7156-61.

Klein, J., Mäntysalo, R. \& Juhola, S., 2016. Legitimacy of urban climate change adaptation: a case in Helsinki. Regional Environmental Change, 16(3), pp.815-826.

Koelble, T.A., 1995. The New Institutionalism in Political Science and Sociology. Comparative Politics, 27(2), pp.231-243.

Lehmann, P. et al., 2015. Barriers and opportunities for urban adaptation planning: analytical framework and evidence from cities in Latin America and Germany. Mitigation and Adaptation Strategies for Global Change, 20(1), pp.75-97.

Lenton, T.M. et al., 2008. Tipping elements in the Earth's climate system. Proceedings of the National Academy of Sciences of the United States of America, 105(6), pp.1786-93.

Lorenz, S. et al., 2017. Adaptation planning and the use of climate change projections in local government in England and Germany. Regional Environmental Change, 17(2), pp.1-11.

Mahoney, J. \& Thelen, K., 2010. A Theory of Gradual Institutional Change. In J. Mahoney \& K. Thelen, eds. Explaining Institutional Change: Ambiguity, Agency, and Power. New York: Cambridge University Press, pp. 1-37.

March, J.G. \& Olsen, J.P., 1989. Rediscovering Institutions: The Organizational Basis of Politics, New York: The Free Press.

Massey, E. \& Huitema, D. 2015.The Emergence of Climate Change Adaptation as a New Field of Public Policy in Europe. Regional Environmental Change, 16(2), pp.553-564.

McDonald, J., 2011. The role of law in adapting to climate change. Wiley Interdisciplinary 
Reviews: Climate Change, 2(2), pp.283-295.

Measham, T.G. et al., 2011. Adapting to climate change through local municipal planning: Barriers and challenges. Mitigation and Adaptation Strategies for Global Change, 16(8), pp.889-909.

Mees, H.L.P., Driessen, P.P.J. \& Runhaar, H. a. C., 2012. Exploring the Scope of Public and Private Responsibilities for Climate Adaptation. Journal of Environmental Policy \& Planning, 14(February 2013), pp.305-330.

Mogelgaard, K., McGray, H. \& Amerasinghe, N.M., 2016. What Does the Paris Agreement Mean for Climate Resilience and Adaptation? World Resources Institute. Available at: http://www.wri.org/blog/2015/12/what-does-paris-agreement-mean-climate-resilience-andadaptation [Accessed November 11, 2016].

Munck af Rosenschöld, J., Rozema, J.G. \& Frye-Levine, L.A., 2014. Institutional inertia and climate change: a review of the new institutionalist literature. Wiley Interdisciplinary Reviews: Climate Change, 5(5), pp.639-648.

Munck af Rosenschöld, J. \& Wolf, S.A., 2017. Toward projectified environmental governance? Environment and Planning A, 49(2), pp.273-292.

Næss, L.O. et al., 2005. Institutional adaptation to climate change: Flood responses at the municipal level in Norway. Global Environmental Change, 15(2), pp.125-138.

Næss, L.O. et al., 2006. Data and processes linking vulnerability assessment to adaptation decision-making on climate change in Norway. Global Environmental Change, 16(2), pp.221-233.

North, D.C., 1990. Institutions, Institutional Change, and Economic Performance, Cambridge: Cambridge University Press.

O'Brien, K. et al., 2007. Why different interpretations of vulnerability matter in climate change discourses. Climate Policy, 7(1), pp.73-88.

O’Brien, K.L. \& Leichenko, R.M., 2000. Double exposure: assessing the impacts of climate change within the context of economic globalization. Global Environmental Change, 10(3), pp. 221-232.

O'Brien, K.L., 2016. Climate change and social transformations: is it time for a quantum leap? Wiley Interdisciplinary Reviews: Climate Change, 7(5), pp.618-626.

O’Riordan, T. \& Jordan, A., 1999. Institutions, climate change and cultural theory: towards a common analytical framework. Global Environmental Change, 9(2), pp.81-93.

Olson, M., 1965. The Logic of Collective Action, Cambridge: Harvard University Press. 
Olsson, P., Bodin, Ö. \& Folke, C., 2010. Building Transformative Capacity for Ecosystem Stewardship in Social-Ecological Systems. In D. Armitage \& R. Plummer, eds. Adaptive Capacity and Environmental Governance. Berlin, Heidelberg: Springer, pp. 263-285.

Ostrom, E., 1990. Governing the Commons: The Evolution of Institutions for Collective Action, Cambridge: Cambridge University Press.

Pahl-Wostl, C., 2009. A conceptual framework for analysing adaptive capacity and multi-level learning processes in resource governance regimes. Global Environmental Change, 19(3), pp.354-365.

Pelling, M., 2011. Adaptation to Climate Change: From Resilience to Transformation. Abingdon, Oxon: Routledge.

Peters, B.G., Pierre, J. \& King, D.S., 2005. The Politics of Path Dependency: Political Conflict in Historical Institutionalism. The Journal of Politics, 67(4), pp.1275-1300.

Pierson, P., 2004. Politics in Time: History, Institutions, and Social Analysis, Princeton: Princeton University Press.

Porter, J.J., Demeritt, D. \& Dessai, S., 2015. The right stuff? Informing adaptation to climate change in British Local Government. Global Environmental Change, 35, pp.411-422.

Powell, W. \& DiMaggio, P.J. eds., 1991. The New Institutionalism in Organizational Analysis, Chicago: University of Chicago Press.

Schmidt, V.A., 2008. Discursive Institutionalism: The Explanatory Power of Ideas and Discourse. Annual Review of Political Science, 11(1), pp.303-326.

Scott, W.R., 1995. Institutions and Organizations, Thousand Oaks: SAGE.

Sjöblom, S. \& Godenhjelm, S., 2009. Project Proliferation and Governance-Implications for Environmental Management. Journal of Environmental Policy \& Planning, 11(3), pp.169185.

Smit, B. \& Wandel, J., 2006. Adaptation, adaptive capacity and vulnerability. Global Environmental Change, 16(3), pp.282-292.

Steffen, W. et al., 2015. Planetary boundaries: Guiding human development on a changing planet. Science, 347(6223), p.1259855.

Storbjörk, S. \& Hedrén, J., 2011. Institutional capacity-building for targeting sea-level rise in the climate adaptation of Swedish coastal zone management. Lessons from Coastby. Ocean and Coastal Management, 54(3), pp.265-273.

Tennekes, J. et al., 2013. Out of the Comfort Zone: Institutional Context and the Scope for 
Legitimate Climate Adaptation Policy. Journal of Environmental Policy \& Planning, 16(2), pp.241-259.

Termeer, C.J.A.M., Dewulf, A. \& Biesbroek, G.R., 2017. Transformational change: governance interventions for climate change adaptation from a continuous change perspective. Journal of Environmental Planning and Management, 60(4), pp.558-576.

Wilbanks, T.J. \& Kates, R.W., 2010. Beyond Adapting to Climate Change: Embedding Adaptation in Responses to Multiple Threats and Stresses. Annals of the Association of American Geographers, 100(4), pp.719-728. 